\section{Original Article}

Check for updates

\section{OPEN ACCESS}

Received: May 8, 2018

Revised: Aug 24, 2018

Accepted: Aug 28, 2018

Correspondence to You Sook Cho, MD, PhD

Division of Allergy and Clinical Immunology,

Department of Internal Medicine, Asan

Medical Center, University of Ulsan College of

Medicine, 88 Olympic-ro 43-gil, Songpa-gu,

Seoul 05505, Korea.

Tel: +82-2-3010-3285

Fax: +82-2-3010-6969

E-mail:yscho@amc.seoul.kr

Ho Joo Yoon, MD, PhD

Department of Internal Medicine, Hanyang

University College of Medicine, 222

Wangsimni-ro, Seongdong-gu, Seoul 04763 , Korea.

Tel: +82-2-2290-8349

Fax: +82-2-2298-9183

E-mail: hjyoon@hanyang.ac.kr

Copyright (c) 2019 The Korean Academy of Asthma, Allergy and Clinical Immunology .

The Korean Academy of Pediatric Allergy and

Respiratory Disease

This is an Open Access article distributed under the terms of the Creative Commons Attribution Non-Commercial License (https:// creativecommons.org/licenses/by-nc/4.0/) which permits unrestricted non-commercial use, distribution, and reproduction in any medium, provided the original work is properly cited.

ORCID iDs

Min-Hye Kim (iD)

https://orcid.org/0000-0002-1775-3733

\title{
Characteristics of Adult Severe Refractory Asthma in Korea Analyzed From the Severe Asthma Registry
}

\author{
Min-Hye Kim (1), ' Sang-Heon Kim $\left(\mathbb{D},{ }^{2}\right.$ So-Young Park $\left(\mathbb{1},{ }^{3}\right.$ Ga-Young Ban $\left(\mathbb{1},{ }^{4}\right.$ \\ Joo-Hee Kim $\left(1,,^{5}\right.$ Jae-Woo Jung $\left(1,{ }^{6}\right.$ Ji Yong Moon $\oplus^{1},{ }^{2}$ Woo-Jung Song $\left(1,{ }^{7}\right.$ \\ Hyouk-Soo Kwon (i), 7 Jae-Woo Kwon (1), ${ }^{8}$ Jae Hyun Lee $\mathbb{1}$, ${ }^{9}$ Hye-Ryun Kang $\left(\mathbb{1},{ }^{10}\right.$ \\ Jong-Sook Park (1)," Tae-Bum Kim (1), ${ }^{7}$ Heung-Woo Park $\left(\mathbb{1 0},{ }^{10}\right.$ Kwang-Ha Yoo $\left(\mathbb{D},{ }^{3}\right.$ \\ Yeon-Mok Oh $(1), 7$ Young-Il Koh $\left(1,,^{12}\right.$ An-Soo Jang $(1),{ }^{11}$ Byung-Jae Lee $\left(\mathbb{1},{ }^{13}\right.$ \\ Young-Joo Cho $\mathbb{D},{ }^{1}$ Sang-Heon Cho $\left(\mathbb{D},{ }^{10}\right.$ Hae-Sim Park $\mathbb{D},{ }^{14}$ Choon-Sik Park $\mathbb{D},{ }^{11}$ \\ Ho Joo Yoon (i), ${ }^{2^{*}}$ You Sook Cho (i) ${ }^{7^{*}}$
}

\section{ABSTRACT}

Purpose: Although mild to moderate asthma is much more common, the morbidity and mortality of severe asthma are much higher. This study was performed to identify and analyze the clinical characteristics of severe asthma in Korea.

Methods: We registered patients with severe refractory asthma into the Severe Asthma Registry supported by the Severe Asthma Work Group of the Korean Academy of Asthma, Allergy and Clinical Immunology. Patients were enrolled since 2010 from the 15 university hospitals nationwide in Korea. Severe asthma was defined according to modified European Respiratory Society/American Thoracic Society criteria. Information on demographics, medical history, pulmonary function tests and skin prick tests was collected; the clinical characteristics of severe asthmatics were analyzed from the collected data.

Results: A total of 489 patients were enrolled with a mean age of $62.3 ; 45 \%$ are male. Sixty percent of patients received Global Initiative for Asthma step 4 treatment, and 30\% received step 5 treatment. The most common comorbidities were allergic rhinitis (58.7\%). Aspirin hypersensitivity was observed in $14.0 \%$. Approximately half (53.9\%) are non-smokers. Atopy was proven in $38.5 \%$ of the patients. Regarding asthma medications, inhaled corticosteroids and long-acting $\beta$-agonist combination inhalers were most commonly prescribed $(96.5 \%)$, followed by leukotriene antagonists $(71.0 \%)$. A recombinant anti-immunoglobulin $\mathrm{E}$ monoclonal antibody (omalizumab) has been used in $1.8 \%$ of the patients. The mean forced 
Sang-Heon Kim (D)

https://orcid.org/0000-0001-8398-4444 So-Young Park (D)

https://orcid.org/0000-0002-5224-3077 Ga-Young Ban (iD)

https://orcid.org/0000-0002-7961-742X Joo-Hee Kim (D)

https://orcid.org/0000-0002-1572-5149

Jae-Woo Jung (iD

https://orcid.org/0000-0002-3411-735X

Ji Yong Moon (ID)

https://orcid.org/0000-0003-2459-3448 Woo-Jung Song (iD)

https://orcid.org/0000-0002-4630-9922

Hyouk-Soo Kwon (iD)

https://orcid.org/0000-0001-7695-997X Jae-Woo Kwon (iD

https://orcid.org/0000-0003-1639-3606 Jae Hyun Lee (D)

https://orcid.org/0000-0002-0760-0071 Hye-Ryun Kang (D)

https://orcid.org/0000-0002-2317-4201

Jong-Sook Park (iD)

https://orcid.org/0000-0003-4128-9085

Tae-Bum Kim (D)

https://orcid.org/0000-0001-5663-0640

Heung-Woo Park (iD

https://orcid.org/0000-0002-6970-3228

Kwang-Ha Yoo (D)

https://orcid.org/0000-0001-9969-2657

Yeon-Mok Oh (iD)

https://orcid.org/0000-0003-0116-4683

Young-Il Koh (iD)

https://orcid.org/0000-0002-5100-9473

An-Soo Jang (iD)

https://orcid.org/0000-0001-5343-023X

Byung-Jae Lee (D)

https://orcid.org/0000-0001-6940-0836 Young-Joo Cho (D)

https://orcid.org/0000-0002-9414-5934

Sang-Heon Cho (iD

https://orcid.org/0000-0002-7644-6469 Hae-Sim Park (D)

https://orcid.org/0000-0003-2614-0303

Choon-Sik Park (iD)

https://orcid.org/0000-0003-2977-0255

Ho Joo Yoon (iD)

https://orcid.org/0000-0002-4645-4863

You Sook Cho (iD)

https://orcid.org/0000-0001-8767-2667

\section{Disclosure}

There are no financial or other issues that might lead to conflict of interest.

vital capacity (FVC), forced expiratory volume in 1 second (FEV1) and FEV1/FVC were 78.7\%, $67.5 \%$ and $67.9 \%$ of predicted values, respectively. The mean Asthma Control Test and quality of life questionnaire scores were 16.5 out of 25 and 59.5 out of 85 , respectively. Conclusions: The baseline characteristics of severe asthma patients in the Korea Severe Asthma Registry were analyzed and reported for the first time. With this cohort, further prospective studies should be performed to search for ways to improve management of severe refractory asthma.

Keywords: Asthma; severe asthma; registry

\section{INTRODUCTION}

Asthma, characterized by chronic airway inflammation and airway hyperreactivity, varies from mild to severe depending on clinical signs and symptoms. ${ }^{1}$ Asthma is one of the most prevalent diseases, accounting for more than $30 \%$ of respiratory diseases according to the Asia-Pacific Burden of Respiratory Diseases (APBORD) surveillance study. ${ }^{2}$ Severe asthma refers to asthma that requires treatment with high-dose inhaled corticosteroids (ICS) to maintain control or that remains uncontrolled despite this treatment. ${ }^{3}$ The prevalence of severe asthma has been reported to be about $5 \%-10 \%,{ }^{47}$ yet it is difficult to determine its exact prevalence. The reason for this is that the definition of severe asthma has not been clearly established and that the term 'severe asthma' has been used to indicate both difficultto-control asthma and severe refractory asthma. ${ }^{7-9}$ However, since the Paris Workshop in 2007, severe refractory asthma began to be distinguished from difficult-to-treat asthma. ${ }^{10,11}$ Difficult-to-treat asthma describes cases that remain uncontrolled due to correctable factors such as environmental exposures, comorbidities, poor compliance, inadequate inhaler technique and other reasons.

Nevertheless, severe asthma is still defined differently by different study groups. For this reason, clinical characteristics of severe asthma have not been clearly identified. Furthermore, subgroups with various clinical features are observed among study subjects with severe asthma, and depending on the heterogeneous phenotypes, future biologic treatment is also expected to vary., ${ }^{3,11}$ Severe asthma accounts for only a small portion of the total asthma population, but it causes a large portion of asthma morbidity and medical resource expenditure..$^{12}$ Therefore, it is important to understand the current epidemics and characteristics of severe asthma. Across the Asia-Pacific region, the economic burden of asthma, chronic obstructive pulmonary disorder (COPD) and rhinosinusitis was examined, and the annual cost per patient with respiratory disease was US $\$ 8,853 .^{2}$ Among them, severe asthma, which accounts for only $10 \%-20 \%$ of total asthma patients, accounts for more than $50 \%$ of the total cost of asthma. ${ }^{13}$ Hence, it is important to determine the economic burden of severe asthma and to use and distribute healthcare resources. Although many studies of severe asthma in Korea have currently been conducted, ${ }^{14-16}$ the status of severe asthma in the community is not precisely characterized. There are many cohort studies in the western countries with severe asthmatics, but there is no assurance that these study results will represent severe asthma patients in Asia. ${ }^{17,18}$ In this study, we report the overall clinical features of Korean severe asthma patients by analyzing data from Severe Asthma Registry, the official severe asthma network, consisting of 15 university hospitals nationwide, supported by the Severe Asthma Work Group of the Korean Academy of Asthma, Allergy and Clinical Immunology (KAAACI). In addition, asthma severity tends to increase as Global 
Initiative for Asthma (GINA) treatment step goes up. ${ }^{19}$ In order to determine which features are more prominent as the severity of asthma increases, we intended to compare the clinical differences according to the GINA treatment steps.

\section{MATERIALS AND METHODS}

\section{Study design}

Starting in 2010, we prospectively enrolled patients with severe asthma from the 15 university hospitals nationwide in Korea. Severe asthma was defined as follows: patients who do not consistently reach a well-controlled state even after GINA treatment step 4 or $5^{20}$; patients who have reached a well-controlled state but have more than 1 urgent care visit a year, need steroid burst treatment more than 3 times a year or experience exacerbation when oral or ICS are reduced 25\%; or patients who have had a near-fatal asthma attack anytime in the past. Demographic information including sex, age, comorbidities, past medical history, pet ownership, smoking history, family history of allergic disease, unscheduled healthcare visits or corticosteroid burst treatment, and asthma-related questionnaires (Asthma Control Test $[\mathrm{ACT}],{ }^{21}$ quality of life questionnaire in adult Korean asthmatics [QLQAKA] ${ }^{22}$ ) were collected from patient questionnaires. Body mass index (BMI), laboratory tests, pulmonary function tests, allergen skin prick test and medication prescription data were provided by physicians. From these data, the characteristics of severe asthma were analyzed. To determine whether there is any difference in clinical features according to disease severity, we compared characteristics of patients receiving GINA treatment step 4 with those of patients receiving step 5 treatment. The study was approved by the Institutional Review Board of the ethics committee of each hospital (Ewha Womans University Mokdong Hospital IRB number: 2013-01-001).

\section{Statistical analysis}

All data with normal distribution are expressed as mean \pm standard deviation or number $(\%)$. Data with non-normal distribution were analyzed by median values. Student's $t$ test or the Mann-Whitney $U$ test was used for continuous variables and chi-square test or Fisher's exact test was used for categorical variables. A $P$ value $<0.05$ was considered significant. All statistical analyses were done using SPSS version 20.0 (IBM Corp., Armonk, NY, USA).

\section{RESULTS}

In total, 489 severe asthmatic patients were enrolled. Mean age was $62.3 \pm 14.0$ years and $45.1 \%$ are male. The mean age at the diagnosis of asthma was 45 years, with an average of 10 years of asthma treatment (Table 1). Comorbid diseases were frequent in the following order: allergic rhinitis, hypertension and gastroesophageal reflux disease (Table 2). Current and exsmokers accounted for $46 \%$ of the patients. Aspirin-exacerbated respiratory disease (AERD) was reported on the questionnaire by $14 \%$ of the the patients. Fourteen percent were pet owners, and $47 \%$ of the patients reported having a family history of allergic diseases, such as asthma, allergic rhinitis, and atopic dermatitis. Atopy was found in approximately one third of the patients. Most of the atopic patients were sensitized to house dust mites, followed by pollen, animals and mold. A history of atopic dermatitis, allergic conjunctivitis and atopy seemed to be more common in the patients receiving GINA treatment step 4, and anxiety disorder seemed to be more prevalent in those receiving GINA treatment step 5, although the differences were not statistically significant. However, a family history of allergic disease 
Table 1. Comparison of baseline characteristics according to GINA guideline treatment step

\begin{tabular}{|c|c|c|c|c|}
\hline Characteristics & Severe asthma $(n=489)$ & GINA step $4(n=293)$ & GINA step $5(n=153)$ & $P$ value \\
\hline Age (yr) & $62.3 \pm 14.0$ & $62.7 \pm 14.0$ & $62.3 \pm 14.1$ & 0.737 \\
\hline Sex (male) & $220(45.1)$ & $129(44.2)$ & $74(48.4)$ & 0.424 \\
\hline BMI $\left(\mathrm{kg} / \mathrm{m}^{2}\right)$ & $24.0 \pm 3.8$ & $24.0 \pm 3.9$ & $23.9 \pm 3.5$ & 0.618 \\
\hline Onset of asthmatic symptoms (yr) & $40.8 \pm 17.4$ & $40.6 \pm 18.0$ & $42.0 \pm 15.1$ & 0.382 \\
\hline Asthma diagnosis (yr) & $44.8 \pm 16.3$ & $45.2 \pm 16.9$ & $44.4 \pm 14.8$ & 0.592 \\
\hline Asthma treatment (yr) & $46.5 \pm 15.8$ & $47.1 \pm 16.5$ & $45.3 \pm 14.6$ & 0.278 \\
\hline Duration of asthma treatment & $10.5 \pm 9.8$ & $10.6 \pm 11.1$ & $10.9 \pm 8.2$ & 0.824 \\
\hline Aspirin hypersensitivity (AERD) & $62 / 444(14.0)$ & $40(15.3)$ & $21(14.5)$ & 0.885 \\
\hline Pet owners & $69(14.1)$ & $43(15.0)$ & $18(11.8)$ & 0.388 \\
\hline Smoking history & - & $12.1 \pm 26.7$ & $13.1 \pm 24.0$ & 0.679 \\
\hline Never smoker & $262(53.9)$ & $156(53.6)$ & $84(54.9)$ & 0.255 \\
\hline Ex-smoker & $164(33.7)$ & $95(32.6)$ & $56(36.6)$ & - \\
\hline Current smoker & $60(12.3)$ & $40(13.7)$ & $13(8.5)$ & - \\
\hline Family history of allergic disease & $224 / 472(47.5)$ & $143(50.9)$ & $58(38.4)$ & 0.015 \\
\hline Atopy & $104 / 270(38.5)$ & $68(40.7)$ & $20(27.8)$ & 0.059 \\
\hline Sensitization to house dust mite & $91(33.7)$ & $59(20.1)$ & $25(16.3)$ & 0.373 \\
\hline Sensitization to pollen & $44(16.3)$ & $36(12.3)$ & $9(5.9)$ & 0.046 \\
\hline Sensitization to animal & 37 (13.7) & $25(8.5)$ & $10(6.5)$ & 0.674 \\
\hline Sensitization to mold & $9(3.3)$ & $8(2.7)$ & $2(1.3)$ & 0.505 \\
\hline
\end{tabular}

Data are presented as mean \pm standard deviation or number $(\%)$.

GINA, Global Initiative for Asthma; BMI, body mass index; AERD, aspirin exacerbated respiratory disease.

Table 2. Comorbidities and past medical histories according to GINA guideline treatment step

\begin{tabular}{|c|c|c|c|c|}
\hline Comorbidities/past medical histories & Severe asthma $(n=489)$ & GINA step $4(n=293)$ & GINA step $5(n=153)$ & $P$ value \\
\hline Allergic rhinitis & $267 / 455(58.7)$ & $164(60.3)$ & $82(55.8)$ & 0.406 \\
\hline Atopic dermatitis & $42 / 480(8.8)$ & $32(11.2)$ & $8(5.2)$ & 0.054 \\
\hline Allergic conjunctivitis & $31 / 482(6.4)$ & $23(8.0)$ & $5(3.3)$ & 0.064 \\
\hline GERD & $61 / 480(12.7)$ & $36(12.6)$ & $15(9.9)$ & 0.438 \\
\hline Sleep apnea & $8 / 479(1.7)$ & $4(1.4)$ & $5(2.6)$ & 0.458 \\
\hline Anxiety disorder & $8 / 479(1.7)$ & $2(0.7)$ & $5(3.3)$ & 0.054 \\
\hline Depressive disorder & 19/482 (3.9) & $12(4.2)$ & $6(3.9)$ & 1.000 \\
\hline Hypertension & $148 / 481(30.8)$ & $79(27.5)$ & $59(38.6)$ & 0.018 \\
\hline Heart failure & $8 / 478(1.7)$ & $3(1.1)$ & $5(3.3)$ & 0.134 \\
\hline Pulmonary tuberculosis & $22 / 475(4.6)$ & $14(4.9)$ & $6(3.9)$ & 0.647 \\
\hline Pneumonia & $43 / 475(9.1)$ & $25(8.8)$ & $14(9.3)$ & 1.000 \\
\hline
\end{tabular}

Data are presented as number (\%).

GINA, Global Initiative for Asthma; GERD, gastroesophageal reflux disease.

and pollen sensitization were significantly more common in the GINA step 4 group, while hypertension was more common in the GINA step 5 group. Other characteristics were not different between the 2 groups (Table 1).

Mean forced vital capacity (FVC), forced expiratory volume in 1 second (FEV1) and FEV1/FVC values were $78.7 \%, 67.5 \%$ and $67.9 \%$, respectively. Mean peripheral blood eosinophil count was $429.1 / \mu \mathrm{L}$, and the proportion of patients with blood eosinophils greater than $300 / \mu \mathrm{L}$ was $41.4 \%$. Sputum eosinophil counts were available in 196 patients; their mean sputum eosinophil count was $17.5 \%$. Among them, 105 (53.3\%) had sputum eosinophil counts more than 3\%. Mean total immunoglobulin $\mathrm{E}$ (IgE) and fractional exhaled nitric oxide (FeNO) were $466.0 \mathrm{IU} / \mathrm{mL}$ and $41.1 \mathrm{ppb}$, respectively (Table 3). Mean FVC $(\%, \mathrm{~mL})$ and FEV1 $(\%, \mathrm{~mL})$ were significantly lower in the patients receiving GINA treatment step 5 than in those receiving step 4 treatment (GINA treatment step 4 vs. $5: 80.2 \% \pm 17.4 \%$ vs. $74.9 \% \pm 16.4 \%, P=0.002 ; 2,661.9 \pm 821.7 \mathrm{~mL}$ vs. $2,397.8 \pm 809.9 \mathrm{~mL}, P=0.002 ; 68.8 \% \pm 17.3 \%$ vs. $64.0 \% \pm 20.5 \%, P=0.019 ; 1,795.9 \pm 642.9$ $\mathrm{mL}$ vs. $1,656.6 \pm 757.2 \mathrm{~mL}, P=0.047$, respectively). Proportions of sputum neutrophils and lymphocytes were higher in patients receiving GINA step 4 treatment $(60.0 \% \pm 32.1 \%$ [step 4] vs. $48.9 \% \pm 33.9 \%$ [step 5], $P=0.028 ; 3.4 \% \pm 9.8 \%$ [step 4 ] vs. $1.0 \% \pm 1.8 \%$ [step 5], $P=0.012$ ) 
Table 3. Comparison of pulmonary function and laboratory test values according to GINA guideline treatment step

\begin{tabular}{|c|c|c|c|c|}
\hline Pulmonary function/laboratory test & Severe asthma $(n=465)$ & GINA step $4(n=278)$ & GINA step $5(n=146)$ & $P$ value \\
\hline Mean FVC (\%) & $78.7 \pm 17.0$ & $80.2 \pm 17.4$ & $74.9 \pm 16.4$ & 0.002 \\
\hline Mean FVC (mL) & $2,590.8 \pm 842.6$ & $2,661.9 \pm 821.7$ & $2,397.8 \pm 809.9$ & 0.002 \\
\hline Mean FEV1 (\%) & $67.5 \pm 18.5$ & $68.8 \pm 17.3$ & $64.0 \pm 20.5$ & 0.019 \\
\hline Mean FEV1 (mL) & $1,761.0 \pm 688.1$ & $1,795.9 \pm 642.9$ & $1,656.6 \pm 757.2$ & 0.047 \\
\hline Mean FEV1/FVC (\%) & $67.9 \pm 13.1$ & $67.9 \pm 12.7$ & $68.0 \pm 14.5$ & 0.975 \\
\hline WBC $(/ \mu L, n=437)$ & $8,820.3 \pm 5,250.0$ & $8,540.7 \pm 4,874.1$ & $8,928.1 \pm 2,864.0$ & 0.381 \\
\hline Blood eosinophil $(\%, n=434)$ & $5.0 \pm 5.7$ & $5.3 \pm 6.4$ & $4.3 \pm 4.4$ & 0.075 \\
\hline Blood eosinophil $(/ \mu \mathrm{L}, \mathrm{n}=433)$ & $429.1 \pm 859.8$ & $464.4 \pm 1,075.2$ & $353.3 \pm 387.1$ & 0.231 \\
\hline Blood eosinophil $\geq 300(/ \mu \mathrm{L})$ & $178 / 430(41.4)$ & $103(41.2)$ & $58(40.0)$ & 0.832 \\
\hline Total IgE (IU/mL, n = 250) & $466.0 \pm 736.0$ & $452.0 \pm 707.4$ & $525.9 \pm 844.6$ & 0.492 \\
\hline \multicolumn{5}{|l|}{ Sputum cell counts $(n=197)$} \\
\hline Macrophages & $21.6 \pm 26.8$ & $16.6 \pm 22.4$ & $30.7 \pm 30.9$ & 0.001 \\
\hline Neutrophils & $55.4 \pm 33.0$ & $60.0 \pm 32.1$ & $48.9 \pm 33.9$ & 0.028 \\
\hline Lymphocytes & $2.5 \pm 7.6$ & $3.4 \pm 9.8$ & $1.0 \pm 1.8$ & 0.012 \\
\hline Eosinophils & $17.5 \pm 26.1$ & $17.0 \pm 26.7$ & $16.5 \pm 23.5$ & 0.899 \\
\hline Sputum eosinophil > 3\% & $105(53.3)$ & $55(48.7)$ & $40(58.8)$ & 0.220 \\
\hline FeNO (ppb) $(n=30)$ & $41.1 \pm 26.4$ & $39.0 \pm 25.2$ & $53.7 \pm 30.9$ & 0.239 \\
\hline
\end{tabular}

Data are presented as mean \pm standard deviation or number $(\%)$.

GINA, Global Initiative for Asthma; FVC, forced vital capacity; FEV1, forced expiratory volume in 1 second; WBC, white blood cells; IgE, immunoglobulin E; FeNO, fractional exhaled nitric oxide.

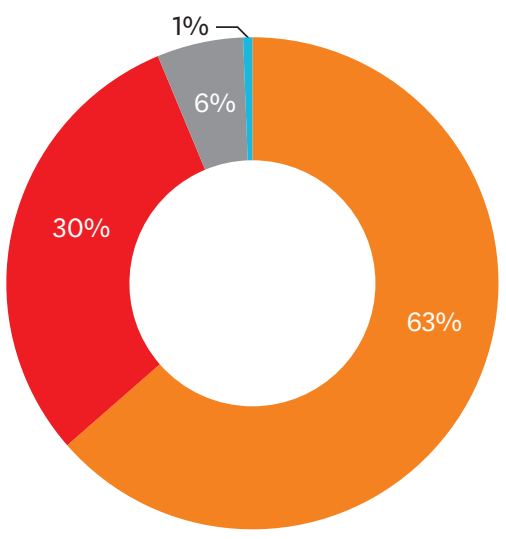

and sputum macrophages were higher in patients receiving GINA step 5 treatment $(16.6 \%$ $\pm 22.4 \%$ [step 4] vs. $30.7 \% \pm 30.9 \%$ [step 5], $P=0.001$ ). There was no significant difference between the GINA step 4 and 5 treatment groups for the other laboratory tests (Table 3).

Ninety-eight percent of the patients were using ICS as a treatment for asthma, and 95\% were using ICS + long-acting beta- 2 agonists (LABA). Three severe asthmatic patients reported that they did not continuously use ICS after they got treated with continuous or intermittent systemic corticosteroids. Among patients using ICS, fluticasone was the most commonly used ICS type, followed by budesonide. The most commonly used oral asthma controllers were leukotriene receptor antagonist (LTRA) and methylxanthine (Fig. 1). Short-acting beta-2 agonists were also used frequently (37.6\%). When comparing the asthma medications according to the GINA treatment step, the use of ICS + LABA was higher in patients receiving GINA treatment step 4 than in those receiving step 5 treatment $(99.3 \%$ vs. $92.8 \%, P<0.001)$.

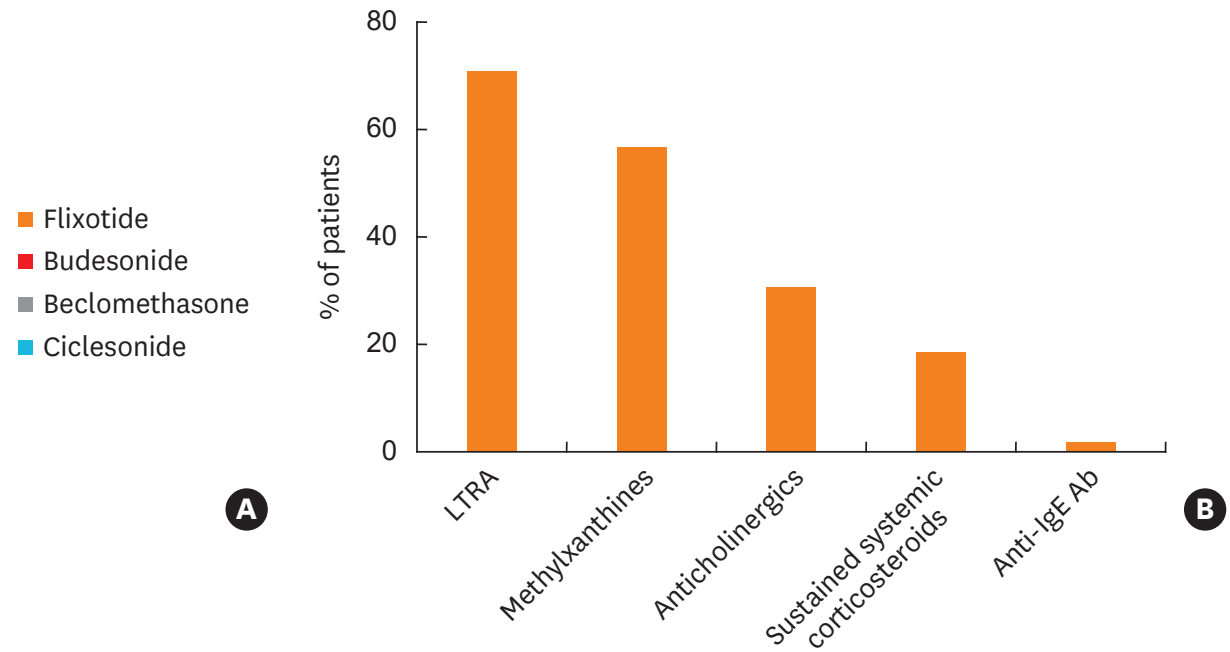

Fig. 1. The composition of ICS types (A). The percentage of use of other controllers or rescue medication (B). ICS, inhaled corticosteroids; LTRA, leukotriene receptor antagonist; IgE, immunoglobulin E; Ab, antibody. 
Table 4. Comparison of prescribed asthma medications according to GINA guideline treatment step

\begin{tabular}{|c|c|c|c|c|}
\hline Asthma medications & Severe asthma $(n=489)$ & GINA step $4(n=293)$ & GINA step $5(n=153)$ & $P$ value \\
\hline \multicolumn{5}{|l|}{ Drugs } \\
\hline ICS+LABA & $472(96.5)$ & $291(99.3)$ & $142(92.8)$ & $<0.001$ \\
\hline ICS+LABA+LTRA & 337 (68.9) & $204(69.6)$ & $104(68.0)$ & 0.747 \\
\hline$I C S+L A B A+L A M A$ & $143(29.2)$ & $89(30.4)$ & $42(27.5)$ & 0.584 \\
\hline LTRA & $347(71.0)$ & $205(71.4)$ & $112(74.2)$ & 0.575 \\
\hline Methylxanthines & $279(57.1)$ & $167(58.6)$ & $92(61.7)$ & 0.538 \\
\hline Anticholinergics & $150(30.7)$ & $89(31.8)$ & $49(32.9)$ & 0.829 \\
\hline Sustained systemic corticosteroids & $92(18.8)$ & $0(0.0)$ & $92(60.1)$ & $<0.001$ \\
\hline Anti-IgE antibody & $9(1.8)$ & $2(0.7)$ & $7(4.6)$ & 0.010 \\
\hline ICS dose in the previous year (mcg/day, budesonide) & $1,102.0 \pm 732.7$ & $1,101.3 \pm 691.4$ & $1,170.1 \pm 776.2$ & 0.340 \\
\hline $\begin{array}{l}\text { Total systemic corticostseroids dose in the previous } \\
\text { year (mg, prednisolone) }\end{array}$ & $802.7 \pm 1,252.1$ & $541.4 \pm 963.9$ & $1,442.4 \pm 1,599.9$ & $<0.001$ \\
\hline
\end{tabular}

Data are presented as mean \pm standard deviation or number (\%).

GINA, Global Initiative for Asthma; ICS, inhaled corticosteroids; LABA, long-acting beta-2 agonists; LTRA, leukotriene receptor antagonist; IgE, immunoglobulin E.

This is probably due to the fact that more patients in the GINA step 5 treatment group were maintained on systemic corticosteroids $(0.0 \%$ vs. $60.1 \%, P<0.001)$. Omalizumab (anti-IgE antibody) tended to be used more frequently in patients receiving GINA treatment step 5 than in those receiving GINA treatment step $4(0.7 \%$ vs. $4.6 \%, P=0.010)$. Although there was no difference in total ICS dose, total systemic corticosteroid dose was significantly higher in patients receiving GINA treatment step 5 than in those receiving step 4 treatment $(541.4 \pm$ $963.9 \mathrm{mg}$ vs. 1,442.4 $\pm 1,599.9 \mathrm{mg}, P<0.001$ ) (Table 4).

The proportion of patients who unexpectedly visited a healthcare facility during the previous year (including unscheduled outpatient clinic visit, emergency room visit or hospitalization) was approximately $15 \%$. Few patients $(0.6 \%)$ were ever admitted to an intensive care unit (ICU) (Fig. 2A). The number of unscheduled outpatient clinic visits was larger in patients receiving step 5 treatment than in those receiving step 4 treatment $(1.92 \pm 1.59$ vs. $3.25 \pm 2.65, P=0.029)$. Other unexpected visits and number of unscheduled visits were not different according to the GINA treatment step (Table 5). Forty-one percent of patients received at least one steroid burst treatment per year, and $24.3 \%$ of patients required more than three steroid burst treatments per year (Fig. 2B). The frequency of systemic corticosteroid burst treatment was also higher in the GINA treatment step 5 group $(2.00 \pm 1.51$ [step 4] vs. $3.10 \pm 1.98$ [step 5], $P<0.001)$.
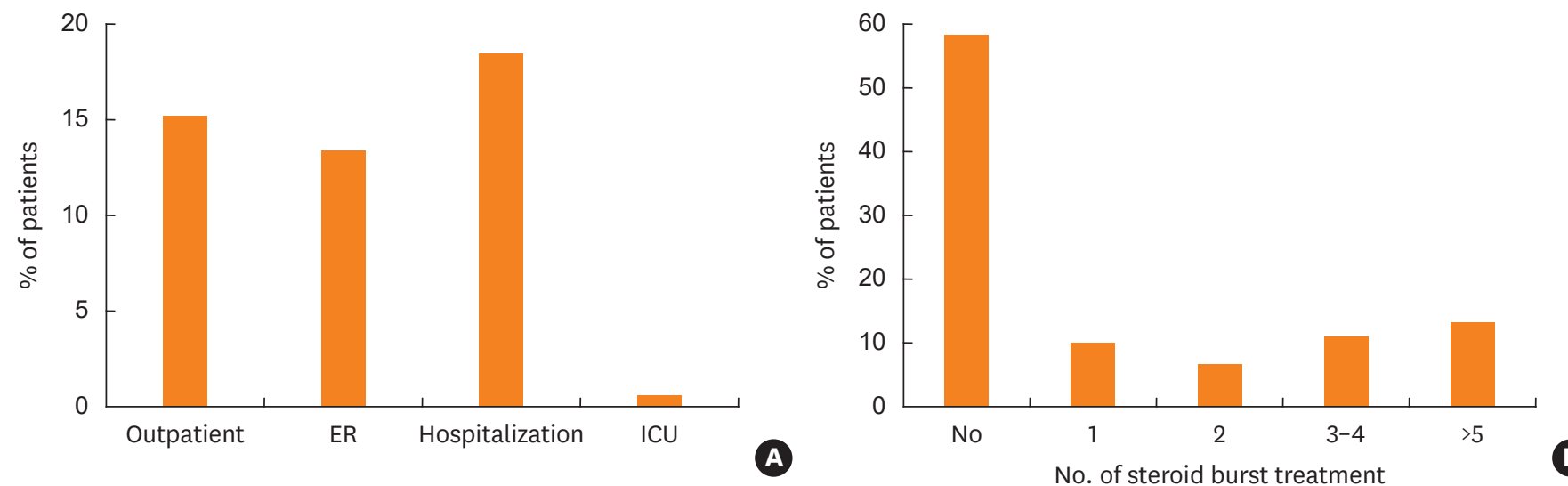

Fig. 2. The percentage of patients who visited a healthcare facility unexpectedly $(A)$ and the percentage of patients who were prescribed systemic corticosteroids burst treatment (B).

$E R$, emergency room; ICU, intensive care unit. 
Table 5. Comparison of unexpected healthcare visits according to GINA guideline treatment step

\begin{tabular}{|c|c|c|c|c|}
\hline Unexpected healthcare use & Severe asthma $(n=489)$ & GINA step $4(n=293)$ & GINA step $5(n=153)$ & $P$ value \\
\hline \multicolumn{5}{|c|}{ Presence of unscheduled visit in the previous year } \\
\hline Outpatient & $75(15.3)$ & $47(16.4)$ & $17(11.3)$ & 0.158 \\
\hline $\mathrm{ER}$ & $65(13.3)$ & $33(11.5)$ & $27(17.9)$ & 0.079 \\
\hline Hospitalization & $89(18.2)$ & $53(18.5)$ & $30(19.9)$ & 0.798 \\
\hline ICU admission & $3(0.6)$ & $1(0.4)$ & $2(1.3)$ & 0.272 \\
\hline \multicolumn{5}{|c|}{ Number of unscheduled visits in the previous year } \\
\hline Outpatient & $2.37 \pm 2.16$ & $1.92 \pm 1.59$ & $3.25 \pm 2.65$ & 0.029 \\
\hline ER & $0.24 \pm 1.44$ & $0.16 \pm 0.47$ & $0.23 \pm 0.56$ & 0.133 \\
\hline Hospitalization & $0.28 \pm 0.81$ & $0.27 \pm 0.76$ & $0.33 \pm 0.95$ & 0.473 \\
\hline ICU admission & $0.006 \pm 0.079$ & $0.004 \pm 0.059$ & $0.013 \pm 0.115$ & 0.327 \\
\hline Systemic corticosteroid burst treatment & $2.34 \pm 1.74$ & $2.00 \pm 1.51$ & $3.10 \pm 1.98$ & $<0.001$ \\
\hline $\mathrm{ACT}(\mathrm{n}=463)$ & $16.5 \pm 5.9$ & $16.2 \pm 6.0$ & $16.7 \pm 5.8$ & 0.397 \\
\hline QLQAKA $(n=437)$ & $59.5 \pm 16.7$ & $60.0 \pm 17.1$ & $58.6 \pm 15.8$ & 0.417 \\
\hline
\end{tabular}

Data are presented as mean \pm standard deviation or number (\%).

GINA, Global Initiative for Asthma; ER, emergency room; ICU, intensive care unit; ACT, asthma control test; QLQAKA, quality of life questionnaire in adult Korean asthmatics.

The mean ACT score was 16.5 out of 25 and the mean QLQAKA score was 59.5 out of 85 . ACT and QLQAKA scores were not different between the 2 treatment groups (Table 5).

\section{DISCUSSION}

In this study we evaluated the current status of severe asthma patients being treated at tertiary university hospitals in Korea and it is the first cohort analysis in real world targeted only severe asthmatic patients in Korea. We found that some clinical features of severe asthma in Korean patients were unique compared to those of patients in other countries, and the burden of severe asthma was substantial. In addition, our study has shown that there is a difference in clinical features among patients with severe asthma according to their severity. Compared to the GINA step 4 treatment group, the GINA step 5 treatment group showed lower lung function, lower allergic tendency and higher neutrophilic airway inflammation. These results suggest that the higher severity in asthma patients, the more likely have an inflammation similar to COPD, rather than an allergic inflammation. We also confirmed that severe asthma is an area of unmet need in asthma, and it is anticipated that further studies based on this cohort will be possible to search for better management strategies for asthma in Korea. The prevalence of severe or difficult-to-treat asthma has been reported to be approximately $5 \%-10 \% .^{4-6}$ In a study conducted in the Netherlands, severe refractory asthma accounted for $3.6 \%$ of all asthma patients. ${ }^{8}$ Because we recruited only patients with severe asthma in this study, it is impossible to estimate the prevalence of severe asthma or proportion of patients with severe asthma among all patients with asthma. However, we have enrolled almost 500 patients from 15 hospitals nationwide so far; thus, the clinical features of severe asthma in Korea can be identified with this severe asthma registry data.

The results of this study showed that severe asthmatic patients in Korea were relatively old with treatment duration of approximately 10 years, and that half of them had a smoking history. Unlike our study, in the National Heart Lung and Blood Institute-sponsored Severe Asthma Research Program (SARP), the age of the subjects was much younger (37 years). ${ }^{17}$ In the European Unbiased Biomarkers for the Prediction of Respiratory Disease Outcomes (U-BIOPRED), the mean age of recruited severe asthmatic patients was in their 50s. ${ }^{18}$ Interestingly, the duration of asthma was more than 20 years in both SARP and U-BIOPRED 
studies, which was much longer than that in our study. It is unclear why the average age and treatment duration of severe asthma differ among Korea and other countries, but it may be due to differences in the basic epidemiology, especially the proportion of smokers. While the proportion of smokers was approximately $50 \%$ in our study, SARP was targeted to non-smoking (less than 5 pack-years of smoking history) asthmatic patients, ${ }^{17}$ and 110 out of 421 (26.1\%) severe asthmatic patients in the U-BIOPRED were smokers or ex-smokers. ${ }^{18}$ The percentage of smokers in the study population or the difference in ethnic background in different countries may have affected the results of the studies. In addition, the inclusion of patients with asthmaCOPD overlap (ACO) could have contributed to the differences among the studies.

In this study, AERD was observed in 14\%. In contrast, AERD accounted for $8 \%$ in the Belgian Severe Asthma Registry, ${ }^{23}$ indicating that AERD is found slightly more often in Korean patients with severe asthma. A family history of allergic diseases such as asthma, allergic rhinitis or atopic dermatitis was observed in approximately half of the patients in our study. However, that information cannot be compared because it was not provided in the SARP and U-BIOPRED studies. In addition, in our study the percentage of patients with atopy was approximately one third, whereas it was over 70\% in the SARP and U-BIOPRED studies..$^{1718}$ This may also reflect an ethnic difference, but because our registry contains more smokers and elderly people than other cohorts, it is possible that there could be many patients with ACO features rather than allergic asthmatics.

With regard to pulmonary function, both the predicted FEV1 value and FEV1/FVC ratio were less than $70 \%$ in this study, which is similar to features of COPD. However, the results of induced sputum analysis showed that the proportion of patients with $>3 \%$ sputum eosinophil count was $53 \%$ and that total IgE, FeNO and atopic rate were also high, showing the characteristics of asthma at the same time. These results mean that severe asthmatic patients in our study have features of ACO. In the SARP data, FEV1 was $74 \%$ and the FEV1/ FVC ratio was 0.7 , which was slightly higher than in our study. ${ }^{17}$ This is probably due to the fact that our study population is older and has more smokers. In the U-BIOPRED study, FEV1 was $67 \%$ and the FEV1/FVC ratio was $0.61-0.64$, which are similar to the results of our study. ${ }^{18}$

Interestingly, in the SARP study, blood eosinophil, sputum eosinophil, and FeNO were $0.2 \%-0.3 \%, 0.7 \%-1.9 \%$ and $24.8-32.8 \mathrm{ppb}$, respectively. ${ }^{17}$ In addition, in the U-BIOPRED study, blood eosinophil, sputum eosinophil and FeNO were $2.9 \%, 2.8 \%-4.1 \%$ and $23.5-26.5$ ppb, respectively; both sets of results are much lower than in our study $(5 \%, 17.5 \%$ and 41.1 $\mathrm{ppb}) .{ }^{18}$ This is probably caused by differences in race, environment, age or measurement method, but the FeNO level is high in patients with elevated eosinophil counts; therefore, patients enrolled in our study may have increased eosinophilic inflammation. ${ }^{24}$ The reason for this difference is still unclear and needs further research.

Although almost all the patients in this study were treated with ICS + LABA, $13 \%$ of the patients visited the emergency room, $18 \%$ and $0.6 \%$ of the patients were admitted to general wards and the ICU, respectively, and $41 \%$ of the patients were treated with steroid burst therapy because of asthma exacerbation within 1 year. In the SARP study, $78 \%$ of the patients were using ICS + LABA. The rate of exacerbation was found to be higher in SARP than in our study. In the SARP study, 30\% of the patients visited ER, and $14 \%$ and $7 \%$ of the patients were admitted to general wards and ICU within 1 year, respectively; however, $28 \%$ of patients in the SARP study were treated with steroid burst more than 3 times a year, which is comparable to $24.3 \%$ in our study (data not shown). ${ }^{17}$ The lower rate of ER visits and ICU admission in 
our study is likely to be related to the higher use of ICS+LABA than in the SARP group. It is also possible that our country has a good accessibility to hospitals or clinics; therefore, there is lower risk of severe exacerbations and patients may be managed earlier even if asthma exacerbation occurs. In the U-BIOPRED study, ICS and LABA were used in over $98 \%$ of severe asthmatics; however, there was no other data about unexpected healthcare use and the number of exacerbations in 1 year was $2.48-2.55 .{ }^{18} \mathrm{In}$ another European population-based study, asthmatic patients using daily ICS were $17 \%-24 \%$, which is much lower compared to this study, while asthma attack in the past year was 36\%-43\% and exacerbation rate was $10 \%-15 \%$, similar to the results of this study. ${ }^{25}$

Severe asthmatic patients were not well controlled according to ACT and QLQAKA scores. ${ }^{21,26}$ SARP did not present data on asthma control and U-BIOPRED used the Asthma Control Questionnaire and the Asthma Quality of Life Questionnaire which are different indices than our study. Thus, direct comparison of asthma control status among the studies was impossible. ${ }^{1718}$ However, severe asthmatics in U-BIOPRED also had poorly controlled asthma and poor quality of life, similar to subjects in our study.

In this study, omalizumab is used in only $1.8 \%$ of the severe asthma patients, which is much less compared to other countries such as the US and many European countries. Recent studies have reported that short-term and long-term therapy with omalizumab showed reduction in symptoms, exacerbations, and medications and improvement in lung functions without any safety concerns. ${ }^{27,28}$ Given the frequent use of systemic corticosteroids for the patients in this study, omalizumab could be more frequently considered as an alternate therapeutic option. However, we have to consider that it is not reimbursed by the Korean insurance system. In addition, it is possible that in this Korean severe asthma registry, the proportion of severe asthmatic patients with IgE-mediated allergic asthma is relatively low, probably due to ethnic difference, although the precise cause should be further studied.

Meanwhile, a large number of severe asthmatic patients has severe eosinophilic asthma, which can be a candidate asthma subtype for other biologics such as anti-interleukin (IL)-5 therapy. ${ }^{29}$ Various biologics including several anti-IL-5 biologics such as mepolizumab, reslizumab, and benralizumab are newly-marketed or are expected to be approved by the Korean Food and Drug Administration for marketing in Korea. Further studies investigating the efficacy of the new biologics and related clinical characteristics in severe eosinophilic asthma should be conducted in the near future.

A comparison of GINA step 4 and 5 treatment groups to determine the difference in characteristics according to severity showed that allergen sensitization rates, family history of allergic diseases and lung functions were lower in patients with higher severity. In contrast, hypertension was more common in the GINA step 5 treatment group. This is consistent with lower lung functions in patients with severe asthma in the SARP study, ${ }^{17}$ which also showed a decrease in the proportion of atopy in severe patients. However, direct comparison is limited because in the SARP study, lung function results varied among clusters classified by atopy status. ${ }^{17}$ Among them, cluster 3 (late-onset nonatopic asthma) and 5 (severe asthma with fixed airflow) showed low rates of atopy. In addition, there was a higher rate of hypertension in the cluster 3 and 5 groups. ${ }^{17}$ Similar to our study, the U-BIOPRED study also showed lower pulmonary functions and lower rates of atopy in patients with severe asthma compared to those with mild to moderate asthma. ${ }^{18}$ Hypertension was not recorded in the U-BIOPRED study and could not be compared. ${ }^{18}$ 
Regarding sputum inflammatory cells, the proportion of macrophages was higher and neutrophils and lymphocytes were lower in the step 5 treatment group than in the step 4 treatment group, and there was no difference in the proportion of eosinophils. Unlike our study, the proportions of sputum eosinophils and neutrophils were higher in patients with severe asthma in both the SARP and U-BIOPRED studies. Further research is needed to elucidate the reasons of this difference.

The rate of ICS + LABA combination prescription was lower in the step 5 group than in the step 4 group, paradoxically, presumably because the patients in the step 5 group were treated with other drugs, such as anti-IgE antibody and systemic corticosteroids. Furthermore, there were more unexpected outpatient visits and corticosteroids burst treatment in patients in the step 5 treatment group, which may also reflect the severity of their condition.

There are several limitations to this study. This study is an analysis of a severe asthmatic patient cohort alone; thus, it is difficult to identify the clinical characteristics of severe asthmatics compared to those of non-severe asthmatic patients. In order to overcome this limitation, comparative analysis with other general asthma cohorts should be performed. In addition, because we used survey questionnaires, the patients' responses could be inaccurate. Despite these limitations, this real-world study is meaningful to understand the current situation and clinical features of Korean severe asthmatic patients.

In conclusion, severe asthmatic patients in Korea had poor asthma control, high frequency of exacerbations, and considerable use of healthcare facilities and asthma medications. This study confirmed the burden of severe asthma through these objective data. This study is also expected to contain useful, basic data for finding and applying future treatments for severe asthma. The severe asthma cohort will be of great help in the understanding of the disease and the affected patients, with more expanded data and analysis in the future.

\section{ACKNOWLEDGMENTS}

This study was supported by a grant from the Korean Academy of Asthma, Allergy and Clinical Immunology.

\section{REFERENCES}

1. Martinez FD, Vercelli D. Asthma. Lancet 2013;382:1360-72. PUBMED | CROSSREF

2. Yoo KH, Ahn HR, Park JK, Kim JW, Nam GH, Hong SK, et al. Burden of respiratory disease in Korea: an observational study on allergic rhinitis, asthma, COPD, and rhinosinusitis. Allergy Asthma Immunol Res 2016;8:527-34. PUBMED | CROSSREF

3. Chung KF, Wenzel SE, Brozek JL, Bush A, Castro M, Sterk PJ, et al. International ERS/ATS guidelines on definition, evaluation and treatment of severe asthma. Eur Respir J 2014;43:343-73. PUBMED | CROSSREF

4. Barnes PJ, Woolcock AJ. Difficult asthma. Eur Respir J 1998;12:1209-18. PUBMED | CROSSREF

5. Busse WW, Banks-Schlegel S, Wenzel SE. Pathophysiology of severe asthma. J Allergy Clin Immunol 2000;106:1033-42. PUBMED | CROSSREF 
6. O'Byrne PM, Naji N, Gauvreau GM. Severe asthma: future treatments. Clin Exp Allergy 2012;42:706-11. PUBMED | CROSSREF

7. American Thoracic Society. Proceedings of the ATS workshop on refractory asthma: current understanding, recommendations, and unanswered questions. Am J Respir Crit Care Med 2000;162:2341-51. PUBMED | CROSSREF

8. Hekking PP, Wener RR, Amelink M, Zwinderman AH, Bouvy ML, Bel EH. The prevalence of severe refractory asthma. J Allergy Clin Immunol 2015;135:896-902. PUBMED | CROSSREF

9. Chung KF, Godard P, Adelroth E, Ayres J, Barnes N, Barnes P, et al. Difficult/therapy-resistant asthma: the need for an integrated approach to define clinical phenotypes, evaluate risk factors, understand pathophysiology and find novel therapies. ERS Task Force on Difficult/Therapy-Resistant Asthma. Eur Respir J 1999;13:1198-208. PUBMED

10. Chanez P, Wenzel SE, Anderson GP, Anto JM, Bel EH, Boulet LP, et al. Severe asthma in adults: what are the important questions? J Allergy Clin Immunol 2007;119:1337-48. PUBMED | CROSSREF

11. Bel EH, Sousa A, Fleming L, Bush A, Chung KF, Versnel J, et al. Diagnosis and definition of severe refractory asthma: an international consensus statement from the Innovative Medicine Initiative (IMI). Thorax 2011;66:910-7. PUBMED | CROSSREF

12. Lang DM. Severe asthma: epidemiology, burden of illness, and heterogeneity. Allergy Asthma Proc 2015;36:418-24. PUBMED | CROSSREF

13. Kim SH, Kim TW, Kwon JW, Kang HR, Lee YW, Kim TB, et al. Economic costs for adult asthmatics according to severity and control status in Korean tertiary hospitals. J Asthma 2012;49:303-9. PUBMED | CROSSREF

14. Kim TB, Jang AS, Kwon HS, Park JS, Chang YS, Cho SH, et al. Identification of asthma clusters in two independent Korean adult asthma cohorts. Eur Respir J 2013;41:1308-14. PUBMED | CROSSREF

15. Kim TB, Park CS, Bae YJ, Cho YS, Moon HB; COREA Study Group. Factors associated with severity and exacerbation of asthma: a baseline analysis of the cohort for reality and evolution of adult asthma in Korea (COREA). Ann Allergy Asthma Immunol 2009;103:311-7. PUBMED | CROSSREF

16. Kim MA, Shin SW, Park JS, Uh ST, Chang HS, Bae DJ, et al. Clinical characteristics of exacerbation-prone adult asthmatics identified by cluster analysis. Allergy Asthma Immunol Res 2017;9:483-90. PUBMED | CROSSREF

17. Moore WC, Meyers DA, Wenzel SE, Teague WG, Li H, Li X, et al. Identification of asthma phenotypes using cluster analysis in the Severe Asthma Research Program. Am J Respir Crit Care Med 2010;181:315-23. PUBMED | CROSSREF

18. Shaw DE, Sousa AR, Fowler SJ, Fleming LJ, Roberts G, Corfield J, et al. Clinical and inflammatory characteristics of the European U-BIOPRED adult severe asthma cohort. Eur Respir J 2015;46:1308-21. PUBMED | CROSSREF

19. Aalbers R, Park HS. Positioning of long-acting muscarinic antagonists in the management of asthma. Allergy Asthma Immunol Res 2017;9:386-93. PUBMED | CROSSREF

20. Global Initiative for Asthma (GINA). Global strategy for asthma management and prevention [Internet]. [place unknown]: Global Initiative for Asthma; 2017 [cited 2017 Feb 28]. Available from: http://ginasthma. org/2017-gina-report-global-strategy-for-asthma-management-and-prevention/.

21. Nathan RA, Sorkness CA, Kosinski M, Schatz M, Li JT, Marcus P, et al. Development of the asthma control test: a survey for assessing asthma control. J Allergy Clin Immunol 2004;113:59-65. PUBMED | CROSSREF

22. Kwon HS, Lee SH, Yang MS, Lee SM, Kim SH, Kim DI, et al. Correlation between the Korean version of Asthma Control Test and health-related quality of life in adult asthmatics. J Korean Med Sci 2008;23:621-7. PUBMED | CROSSREF

23. Schleich F, Brusselle G, Louis R, Vandenplas O, Michils A, Pilette C, et al. Heterogeneity of phenotypes in severe asthmatics. The Belgian Severe Asthma Registry (BSAR). Respir Med 2014;108:1723-32. PUBMED | CROSSREF

24. Yune S, Lee JY, Choi DC, Lee BJ. Fractional exhaled nitric oxide: comparison between portable devices and correlation with sputum eosinophils. Allergy Asthma Immunol Res 2015;7:404-8. PUBMED | CROSSREF 
25. Siroux V, Basagaña X, Boudier A, Pin I, Garcia-Aymerich J, Vesin A, et al. Identifying adult asthma phenotypes using a clustering approach. Eur Respir J 2011;38:310-7. PUBMED | CROSSREF

26. Schatz M, Sorkness CA, Li JT, Marcus P, Murray JJ, Nathan RA, et al. Asthma control test: reliability, validity, and responsiveness in patients not previously followed by asthma specialists. J Allergy Clin Immunol 2006;117:549-56. PUBMED | CROSSREF

27. Menzella F, Galeone C, Formisano D, Castagnetti C, Ruggiero P, Simonazzi A, et al. Real-life efficacy of omalizumab after 9 years of follow-up. Allergy Asthma Immunol Res 2017;9:368-72. PUBMED | CROSSREF

28. Li J, Kang J, Wang C, Yang J, Wang L, Kottakis I, et al.; China Omalizumab Study Group. Omalizumab improves quality of life and asthma control in chinese patients with moderate to severe asthma: a randomized phase iii study. Allergy Asthma Immunol Res 2016;8:319-28. PUBMED | CROSSREF

29. Fajt ML, Wenzel SE. Development of new therapies for severe asthma. Allergy Asthma Immunol Res 2017;9:3-14.

PUBMED | CROSSREF 